\title{
A study on determining the opinions and attitudes of community pharmacists about non-pharmaceutical medicinal products
}

\author{
Gizem GÜLPINAR ${ }^{1 *}$, Servet DOLU ${ }^{1}$, Mehmet Barlas UZUN ${ }^{1}$, Gülbin ÖZÇELİKAY ${ }^{1}$ \\ 1 Department of Pharmacy Management, Faculty of Pharmacy, Ankara University, Ankara, Turkey. \\ * Corresponding Author. E-mail: gaykac@gmail.com (G.G.); Tel. +90-312-203 31 28; ORCID No: 0000-0001-6720-1235.
}

Received: 25 November 2017 / Revised: 29 May 2018 / Accepted: 01 June 2018

\begin{abstract}
Social change and changing needs of today's people bring about a service concept that includes both prescription drugs and non-prescription drugs (over the counter medicines and parapharmaceuticals) are offered to clients. Community pharmacists who are the most accessible healthcare providers begin to focus on selling (parapharmaceuticals) non-pharmaceutical medicinal products (NPMPs) that are seen more profitable and require less bureaucratic processes. Assuming that the dilemmas often experienced by community pharmacists between the "businessman" and "healthcare giver" roles could affect their attitudes and opinions about NPMPs. The study, which is designed from this point of departure, is aimed at revealing the opinions of community pharmacists about NPMPs, their knowledge NPMPs and their attitudes such as sales of these products and their policy arrangements. A face to face questionnaire was distributed to 244 community pharmacists in Ankara. According to the results, it was determined that the rate of NPMP sales in total turnover and the pharmacy settlement affect the opinions and attitudes on the subject of the community pharmacists. Most of the pharmacists' "business owner" roles have been shown to influence their attitudes towards drugs and NPMPs, whether their NPMP sales are excessive or not.
\end{abstract}

KEYWORDS: Community pharmacist; community pharmacy; non-drug products; ethical dilemma; opinion and attitude.

\section{INTRODUCTION}

In Turkey, as well as around the world, the pharmaceutical and NPMP market has a structure composed of products delivered to individuals through retail outlets and at the same time through pharmacies.

In Turkey, the Regulation on the Classification of Medicinal Products for Human Use, published in the Official Gazette dated Febuary 17, 2005 and numbered 25730, human products are classified into two categories as prescription drugs and non-prescription drugs. A product should be sold only by prescription according to some criterion. These are determined as below [1]:

- Even if used correctly, they pose a direct or indirect health hazard if not used under medical supervision.

- They pose a direct or indirect health hazard as a consequence of misuse.

- Active substance(s) and their biological activity require further investigation.

In Turkey, as well as most countries, OTCs are medicines licensed at national pharmaceutical markets to be purchased without a medical prescription, usually from community pharmacies on the contrary to prescription-only medicine (POM) [2]. They are safe for short term use and effective for minor common diseases. As directed on the label, a pharmacist's advice is sufficient for safety use [3]. OTCs don't require a prescription by a health professional however that doesn't mean it is harmless. They also contain active substances like prescription drugs and some side effects can be seen when used (4). For example; antiseptics, analgesics, antitussives, antihistamines, antifungals are the OTC categories sold in pharmacies in Turkey.

According to WHO (World Health Organization) a drug is defined "a substance that can be used to modify or examine physiological systems or pathological conditions for the benefit of the patient". In Turkey, the Act on Pharmaceuticals and Medical Preparations numbered 1262, describes drug as "a substance used

How to cite this article: Gülpınar G, Dolu S, Uzun MB, Özçelikay G. A study on determining the opinions and attitudes of community pharmacists about non-pharmaceutical medicinal products. J Res Pharm. 2019; 23(1): 147-155. 
for diagnosis, cure, sedation, treatment or disease prevention registered in a pharmacopoeia or formulary". Except from OTCs there is another category called parapharmaceuitcals (non-pharmaceutical medicinal products) which are directly or indirectly associated with health care and are defined as products that do not correspond to the legal definition of a drug mentioned. Despite all these definitions there is no consensus on scientific definition of the difference between OTCs and NPMPs. The main reason for the ambiguity between these two categories is that there are differences in the legal regulations of these products. Although there are many different rules and regulations for production and marketing of NPMPs, there is no common regulation for all of them. [5]. The Figure 1 is thought to be helpful to understand this classification more clearly.

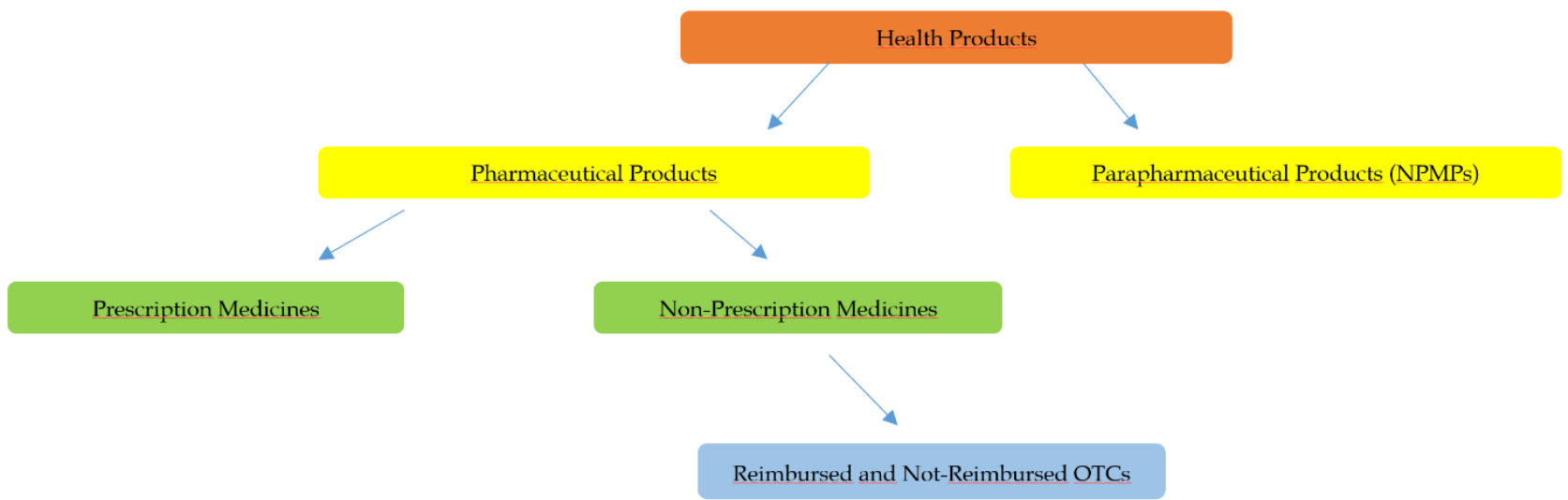

Figure 1. The classification of health products.

Legislation on NPMPs in Turkey

In Turkey, the Regulation on Pharmacists and Pharmacies, published in the Official Gazette dated April 12, 2014 and numbered 28970, also specifies the products that are obligatory to be sold in community pharmacies. The products to be sold exclusively only in pharmacies are:

- All human medicines with prescription or non-prescription,

- Traditional herbal medicinal products licensed from the Turkish Medicines and Medical Devices Agency,

- Homeopathic medicinal products subject to the permission of Turkish Medicines and Medical Devices Agency,

- Dietary foods for special medical purposes, including enteral nutritional products, and baby foods for special medical purposes.

According to the regulation mentioned above, the following products can also be sold in community pharmacies:

- Food supplements produced or imported by permission, license or price from the relevant ministry,

- Drugs, chemical substances and other health products used in pharmaceuticals and agriculture,

- Veterinary medicinal products, excluding veterinary biological products,

- Cosmetic products

- Medical supplies identified by the institution

- All children's products used in breast milk and nutritional deficiency and all supporting products used in adults with metabolic disorders,

- Publications that provide health information to patients approved by the Ministry of Health [6].

Considering the products sold in community pharmacies, it can be said that NPMPs are the products do not need any license or any permission from Ministry of Health to be sold in the market in Turkey. Thus, NPMPs offered to consumers in community pharmacies in Turkey can be listed as follows:

1. Herbal Products (Drugs, herbal teas, phytotherapeutics, phytopharmaceuticals, nutraceuticals)

2. Baby foods/formulas

3. Cosmetic products

4. Medical Supplies

a. Biocidal Products

5. Mother and baby care products

6. Homeopathy products

7. Food supplements

8. Sportmen food 
The differences between cosmetics, medical devices and health products can be shown in Figure 2. To create a common and understandable legal regulation in Turkey, these definitions should be made clearly. The question of how to organize all these different areas is still a matter of curiosity. For example, a distinction between medicinal products and other products (such as cosmetics, food supplements, biocidal products, and combinations thereof) may be useful.

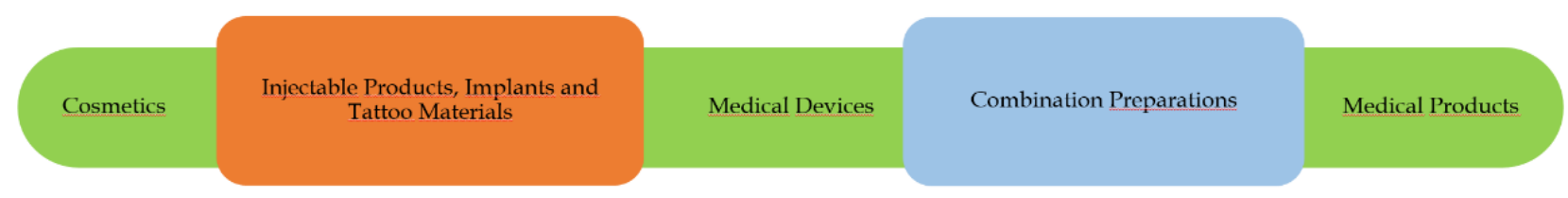

Figure 2. The differences between products.

In Turkey, Social Security Institution (SSI) is payer and decision making body of Turkish Government for drug reimbursement [7]. Community pharmacists have to fulfill some bureaucratic procedures when they give a prescription medicine or reimbursable OTC product in order to get reimbursement from SSI. To give a prescription medicine or a reimbursable OTC to a patient, community pharmacists have to enter the information on prescription into a software system called Medula Pharmacy that SSI obliging pharmacists to use. In Medula Pharmacy software system, some requirements have to be filled by pharmacists for example, patient's citizen ID, the physician's registration number etc. so as to dispense medicines. The system also keeps track of all the medications provided to the patient so far, prevents unnecessary dispensation, and offers replacements whenever a specific product is not available. Finally, the system is used by the SSI for the reimbursement of medicines [8]. Additionally, Medical Enforcement Declaration (MED) proposed by SSI specifies all criterion that a pharmacist should pay attention while registering the prescription into Medula Pharmacy software system [9]. For example, when a patient with prescription of an antibiotic applies to a pharmacy, pharmacists have to counsel the patient initially on the other hand in order to dispense the prescription medicine to patient they have to pay attention what an antibiotic prescription should contain according to MED. To give an example, to be reimbursed of an antidepressant by SSI the active substance and dose that physician prescribes have to be appropriate that was specified in MED. However MED is often updated and reimbursement criterion is changed constantly.

Social change and the changing needs of today's people have led to the development of a medical service concept that includes NPMPs as well as medicinal products. Community pharmacists have begun to focus on sales of NPMPs that are more profitable and require less bureaucratic procedures than prescription medicines mentioned above. As a health organization as well as a business, many ethical dilemmas and problems are faced with the necessity of maintaining the continuity of pharmacies. The ethical responsibility of pharmacists in selling NPMPs as much as medicines is a matter of debate. The opinions, suggestions and attitudes of the community pharmacists involved in presenting the NPMPs to the consumer will be a guideline for the legislator in order to make a clear definition of these products and to make the best legislation.

This study aims to reveal the opinions, knowledge, attitudes of community pharmacists about NPMPs and their opinions on policy regulations.

\section{RESULTS}

According to the demographic data 136 (55.7\%) of the 244 pharmacists participating in the study were female. $37.1 \%$ of community pharmacists are in the age range of $24-35,35.7 \%$ are in the age of $36-50,26.2 \%$ are in the age range of 50 and more. Community pharmacies are grouped as neighborhood pharmacies, pharmacies close to the family health center, pharmacies close to the hospital, district pharmacies and pharmacies close to a shopping center or a crowded place (Table 1). Pharmacists stated that they sold food supplement $(87.3 \%)$, mothers-baby products $(86.5 \%)$ and herbal products $(84 \%)$ in the scope of NPMPs respectively (Table 2). 
Table 1. Location of community pharmacies participated in the survey.

\begin{tabular}{lll}
\hline \multicolumn{1}{c}{ Location } & Frequance (n) & Percentage (\%) \\
\hline Neighborhood & 93 & 38,1 \\
Pharmacies near a family health center & 60 & 24,6 \\
Pharmacies in a shopping center or on a street & 50 & 20,5 \\
Pharmaceis closed to hospital & 31 & 12,7 \\
Pharmacies in a district & 10 & 4,1 \\
TOTAL & 244 & 100,0 \\
\hline
\end{tabular}

The distribution presenting the part of NPMPs in their total turnover is shown in Figure 1. Most of the community pharmacists (62\%) sell NPMPs as a percentage of 10-30\% according to their total drugs in their pharmacies. Less than half of the community pharmacists (21\%) sell NPMPs in their pharmacies as a percentage of $31-50 \%$ in their total turnover. According to Figure 1, the sold NPMPs that constitute half of the total turnover and more is in small part of community pharmacies $(17.2 \%)$.

Table 2. The sales percentages of NPMPs held by pharmacists participated in the survey.

\begin{tabular}{ll}
\hline NPMPs & Percentage of Sales (\%) \\
\hline Food supplements & 87.3 \\
Mother \& baby products & 86.5 \\
Herbal drugs & 84 \\
Cosmetics & 57.4 \\
Medical \& orthopedics & 33.6 \\
Sportsman food & 5.7 \\
\hline
\end{tabular}

Percentages of sales of NPMPs that participant pharmacists have in their pharmacies are shown in Table 2. According to participants mothers-baby products, food supplements and herbal drugs are the best-selling product groups.

The answers given by the participants in the second part of the questionnaire about the legal regulations of the NPMP are given in Table 3.

Table 3. Opinions of community pharmacists on possible legal regulations about NPMPs.

(1: Totally agree; 2: Agree; 3:Undecided; 4: Disagree; 5:Totally disagree)

\begin{tabular}{|c|c|c|c|c|c|c|c|c|c|c|}
\hline \multirow[t]{2}{*}{ STATEMENTS } & \multicolumn{2}{|l|}{1} & \multicolumn{2}{|l|}{2} & \multicolumn{2}{|l|}{3} & \multicolumn{2}{|l|}{4} & \multicolumn{2}{|l|}{5} \\
\hline & $\mathbf{n}$ & $\%$ & $\mathbf{n}$ & $\%$ & $\mathbf{n}$ & $\%$ & $\mathbf{n}$ & $\%$ & $\mathbf{n}$ & $\%$ \\
\hline $\begin{array}{l}\text { NPMPs should be sold only in } \\
\text { pharmacies. }\end{array}$ & 106 & 43.4 & 77 & 31.6 & 9 & 3.7 & 40 & 16.4 & 12 & 4.9 \\
\hline $\begin{array}{l}\text { I think public should ask for } \\
\text { information concerning NPMPs from } \\
\text { pharmacists. }\end{array}$ & 185 & 75.8 & 36 & 14.8 & 8 & 3.3 & 11 & 4.5 & 4 & 1.6 \\
\hline $\begin{array}{l}\text { The public should be informed by } \\
\text { direct-to-consumer advertising about } \\
\text { NPMPs. }\end{array}$ & 16 & 6.6 & 16 & 6.6 & 14 & 5.7 & 59 & 24.2 & 138 & 56.6 \\
\hline $\begin{array}{l}\text { I think we need to go through the data } \\
\text { matrix applications in NPMPs. }\end{array}$ & 144 & 59.1 & 72 & 29.5 & 4 & 1.4 & 2 & 0.9 & 22 & 9.1 \\
\hline $\begin{array}{l}\text { Some weight control products, some } \\
\text { food supplements and dermocosmetic } \\
\text { products should be added to Social } \\
\text { Security reimbursement list. }\end{array}$ & 150 & 61.5 & 31 & 12.7 & 11 & 4.5 & 13 & 5.3 & 39 & 16.0 \\
\hline $\begin{array}{l}\text { I believe that NPMPs direct-to- } \\
\text { consumer advertising can inform the } \\
\text { patient adequately. }\end{array}$ & 3 & 1.2 & 4 & 1.6 & 5 & 2.0 & 36 & 14.8 & 196 & 80.3 \\
\hline $\begin{array}{l}\text { I believe that direct-to-consumer } \\
\text { advertising can increase the sales of } \\
\text { NPMPs. }\end{array}$ & 74 & 30.3 & 63 & 25.8 & 55 & 22.5 & 39 & 16.0 & 13 & 5.3 \\
\hline $\begin{array}{l}\text { I believe that direct-to-consumer } \\
\text { advertising can increase the } \\
\text { consumption of NPMPs. }\end{array}$ & 113 & 46.3 & 99 & 40.6 & 14 & 5.7 & 13 & 5.3 & 5 & 2.0 \\
\hline
\end{tabular}


The pharmacists' opinions on the legal regulations of NPMPs were compared with the distribution of NPMPs in their total turnover and the localization of their pharmacies. The results obtained according to the statistical tests are evaluated below.

Pharmacists with a high share of NPMPs (50\% and over) in their total turnover are more likely to argue that NPMPs should be sold in pharmacies and information about these products must be obtained from the pharmacists $(\mathrm{p}<0,05)$ (Figure 3).

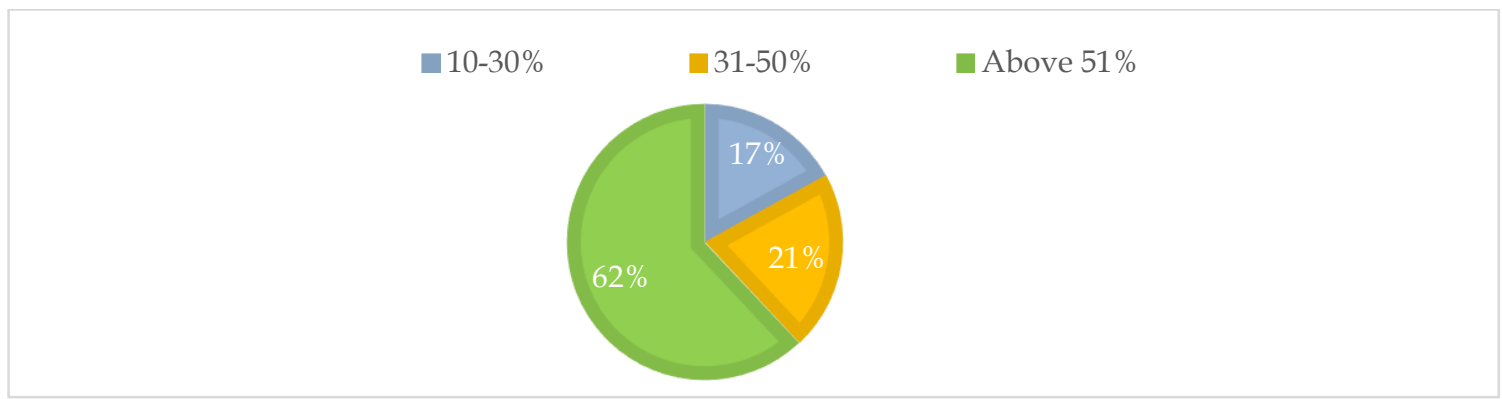

Figure 3. The share of NPMPs that community pharmacists' have in their pharmacies in total turnover

Localization of pharmacies affect pharmacists' opinions on the statement about some dermocosmetic products and food supplements should be added to the SSI reimbursement list $(\mathrm{p}<0.05)$. Pharmacies closed to hospital and neighborhood pharmacies were found to be more willing to take these products to the reimbursement list.

Pharmacists who claim that NPMPs should be included on the reimbursement list are mostly pharmacists whose share of NPMPs is low (10-20\%) in their total turnover.

Pharmacists who are near hospitals, neighbors and family health centers reported more frequently that they did not agree with the statement that they prefer NPMPs because they are more profitable than medicines $(\mathrm{p}<0.05)$ (Table 4).

Table 4. Attitudes of community pharmacists about NPMPs that they have in their pharmacies.

\begin{tabular}{|c|c|c|c|c|c|c|c|c|c|c|}
\hline \multicolumn{11}{|c|}{ (1: Totally agree; 2: Agree; 3:Undecided; 4: Disagree; 5:Totally disagree) } \\
\hline \multirow[t]{2}{*}{ STATEMENTS } & \multicolumn{2}{|l|}{1} & \multicolumn{2}{|l|}{2} & \multicolumn{2}{|l|}{3} & \multicolumn{2}{|l|}{4} & \multicolumn{2}{|l|}{5} \\
\hline & $\mathbf{n}$ & $\%$ & $\mathbf{n}$ & $\%$ & $\mathbf{n}$ & $\%$ & $\mathrm{n}$ & $\%$ & $\mathbf{n}$ & $\%$ \\
\hline $\begin{array}{l}\text { I much prefer NPMPs because it is } \\
\text { more profitable than prescription } \\
\text { medicines. }\end{array}$ & 15 & 6.1 & 15 & 6.1 & 3 & 1.2 & 69 & 28.3 & 142 & 58.2 \\
\hline $\begin{array}{l}\text { I definitely recommend nutritional } \\
\text { supplements to my patients who } \\
\text { want nonprescription drugs. }\end{array}$ & 10 & 4.1 & 13 & 5.3 & 2 & 0.8 & 24 & 9.8 & 195 & 79.9 \\
\hline $\begin{array}{l}\text { I do not give information about food } \\
\text { supplements without a request from } \\
\text { client. }\end{array}$ & 1 & 0.4 & 6 & 2.5 & 1 & 0.4 & 60 & 24.6 & 176 & 72.1 \\
\hline $\begin{array}{l}\text { I recommend more NPMP according } \\
\text { to the needs of the client that has } \\
\text { better economic income. }\end{array}$ & 15 & 6.1 & 40 & 16.4 & 12 & 4.9 & 61 & 25.0 & 116 & 47.5 \\
\hline
\end{tabular}

Pharmacies at the shopping center or on the street $(\mathrm{p}<0,05)$, are more likely to advocate that products that contribute to the ability of pharmacies to survive as a business are mostly NPMPs. Accordingly, community pharmacists at the shopping center or on the street where the sale of NPMPs is more common are more likely to accept that information on medicinal products is more than medicines $(\mathrm{p}<0.05)$.

Pharmacists with high NPMP sales (50\% and over) are more likely to agree that NPMPs have a higher role on sustaining the continuity of pharmacies as a business ( $\mathrm{p}<0.05)$. Similarly, pharmacists $(50 \%$ and over $)$ who had a high level of sales of NPMPs stated that the consumers had more information request about NPMPs from pharmacists $(\mathrm{p}<0.05)$ (Table 5).

The view that vocational training courses to be organized on NPMPs would be beneficial is supported more by pharmacists with low sales of NPMPs $(\mathrm{p}<0.05)$ (Table 5). 
Table 5. Community pharmacists' opinions about the regulations on NPMPs.

(1: Totally agree; 2: Agree; 3:Undecided; 4: Disagree; 5:Totally disagree)

\begin{tabular}{|c|c|c|c|c|c|c|c|c|c|c|}
\hline \multirow[t]{2}{*}{ STATEMENTS } & \multicolumn{2}{|l|}{1} & \multicolumn{2}{|l|}{2} & \multicolumn{2}{|l|}{3} & \multicolumn{2}{|l|}{4} & \multicolumn{2}{|l|}{5} \\
\hline & $\mathbf{n}$ & $\%$ & $\mathbf{n}$ & $\%$ & $\mathbf{n}$ & $\%$ & $\mathbf{n}$ & $\%$ & $\mathbf{n}$ & $\%$ \\
\hline $\begin{array}{l}\text { With the sale of NPMPs, } \\
\text { pharmacies remain standing. }\end{array}$ & 44 & 18.0 & 49 & 20.1 & 12 & 4.9 & 89 & 36.5 & 50 & 20.5 \\
\hline $\begin{array}{l}\text { from pharmacist about NPMPs } \\
\text { is more than medicines. }\end{array}$ & 94 & 38.5 & 78 & 32.0 & 15 & 6.1 & 34 & 13.9 & 23 & 9.4 \\
\hline $\begin{array}{l}\text { I think the spread of NPMPs } \\
\text { increases sales rate from the } \\
\text { internet. }\end{array}$ & 222 & 91.0 & 12 & 4.9 & 4 & 1.6 & 4 & 1.6 & 2 & 0.8 \\
\hline $\begin{array}{l}\text { I think that continuous learning } \\
\text { organized regarding NPMPs } \\
\text { can be helpful for pharmacists. }\end{array}$ & 166 & 68.0 & 58 & 23.8 & 7 & 2.9 & 11 & 4.5 & 2 & 0.8 \\
\hline
\end{tabular}

\section{DISCUSSION}

Most of the pharmacists participating in the study $(75 \%)$ think that NPMPs must be sold only in pharmacies. The reason for pharmacists' thinking like that can be the financial problems of community pharmacies in Turkey [4]. Thus, to maintain their business pharmacists would like to benefit from all the economic products related to welfare of a person.

A study of traditional herbal medicinal products reveals that pharmacists provide information by evidence based to consumers who have information deficiencies related to all medicinal herbal products [1012]. Even pharmacists are sometimes inadequate and refresh the information about NPMPs being sold outside pharmacies might cause unwanted situation.

Based on the results of our work, it appears that pharmacies located near the hospital and neighborhood pharmacies are more willing to take the NPMPs to the reimbursement list. Also, pharmacists with low sales of NPMPs have the same idea. Yüksel's study has shown that consumers are less willing to pay nonprescription drugs from pharmacies near the hospitals [13]. Thus, pharmacists and consumers may have disagreement about the price of these products, therefore pharmacists claim to take the NPMPs to the reimbursement list can be reasonable. With getting the NPMPs' to the reimbursement system, pharmacists no longer have disagreement with their patients about the price of these products.

Pharmacists with high NPMP sales are more likely to support the idea of selling these products only in pharmacies. The idea behind this opinion can be explained that pharmacists do not want to give up the NPMPs that they get a significant part of their revenue. Additionally, pharmacists, who have high sales of NPMPs, have been more supportive of the need to obtain information about NPMPs from pharmacists. In a similar study about natural health products pharmacists described themselves in a consultative role. They expressed that they have a responsibility to look up the information for natural health products because they are supposed to be the accessible information provider [14].

Pharmacists selling less NPMPs, are less sensitive about the sales of these products outside the pharmacy and obtaining information about these products only from a pharmacy. This phenomenon can be interpreted as the fact that the pharmacists do not prefer to give counseling about the products which they get less income. Pharmacists may experience some situations that can create conflict of interest. Thus, pharmacists have professional obligations to counsel patients that could be undermined by financial incentives [15].

Pharmacists whose pharmacies are located in more crowded places have stated that they prefer to sell NPMPs because they are more profitable than medicines. Similarly, Boon and colleagues emphasized that natural health products are more profitable [16]. At the same time, pharmacies at the shopping center or on the street participating in the opinion of by selling the products which are more contributes to the survival of pharmacies as a business are NPMPs more. This result shows that pharmacists whose pharmacies are in crowded places would like to sell more of these products. The pharmacists also give importance to the sale of medicines and medicinal products in addition to patient counseling due to their role as business owners. In the world, the functioning of the pharmacy profession is on the level of patient-centered counseling, which should make pharmacists more dominant than their distributive roles [17-20]. Focusing on selling NPMPs rather than medicines by the pharmacists whose pharmacies are in crowded places because of profitability may mean that they perceive themselves only as "distributor pharmacist" or "business owner". This situation 
can be interpreted as a result of the crisis of professional identity. The gap between the work done and the job descriptions of the pharmacists must be filled and new definitions and regulations should be made about the functioning of the pharmacy profession.

Most of the pharmacists participating in the study $(80.3 \%)$ think that pharmaceutical advertising will not be informed the consumer adequately. In a study, pharmacists have stated that advertisements often emphasize that all medicinal products are safe. Therefore, they have declared that product advertisements are inadequate when making decisions about health [21]. In another study conducted in 2008, pharmacists evaluated OTC product advertisements on the market and found that almost half of the advertisements examined were not prepared in the way that the patient or consumer could make the right decision [22]. For this reason, it should be emphasized on the legislative regulations to be done by considering that the advertisement of medicinal products cannot transfer enough and correct information to the consumer. At the same time, it should be taken into consideration when laws are being enacted that most of the community pharmacists $(88.6 \%)$ demand the adoption of data matrix in NPMPs.

While most participants $(68 \%)$ indicated that vocational training courses to be organized about NPMPs would be beneficial, it was highly likely that pharmacists with low sales of NPMPs would be willing to do so. Pharmacists with this view may assume that organizing vocational training might eliminate the lack of information. By eliminating the lack of information, these products are thought to be able to support their sales.

It seems that pharmacists ( $50 \%$ and over) who have high sales of NPMPs are more likely to argue that the demand of information from pharmacists is higher for NPMPs than for medicines. Pharmacists with high sales of NPMPs might have less demand for vocational training because they are also selling them and they do not need extra training. It has been emphasized that in many studies community pharmacists have inadequate knowledge about complementary and alternative medicines and that training in this regard is necessary $[12,23,24]$.

\section{CONCLUSION}

As a result, the businessman roles of most of the community pharmacists participating in the study, whether have high or low sales of NPMP, influence their attitudes towards NPMPs and medicines. The reason why they would like to focus on selling the products to make profit to the pharmacy could be a desire and the instinct to provide the continuity of the business. Preferring to sell the products depending on whether they are reimbursable or not can be considered as loss of professional value as a result of the professional identity crisis. Therefore, courses which could contribute to the internalization of professional values and to provide professional identity formation such as pharmacy ethics should immediately be included in the undergraduate curricula as well as post graduate training.

\section{MATERIALS AND METHODS}

\subsection{Questionnaire}

In this study, a questionnaire form prepared for community pharmacists in Ankara was used to collect data. In order to evaluate the point of view of the community pharmacists in Turkey in terms of sales of NPMPs in pharmacies, a literature study on the subject was conducted first. Questionnaire was formed by considering similar and related researches.

The questionnaire was formed in two parts. In the first part; some questions were asked to reflect the demographics of the pharmacists (age, sex, etc.). In the second part, there are statements about pharmacists' perspectives on NPMPs sold in community pharmacies and their attitudes towards this topic. Statements are grouped under three dimensions. These are; "opinions and suggestions of community pharmacists about possible legislative arrangements", "attitudes of pharmacists to NPMPs in pharmacies" and "opinions of community pharmacists on current NPMP policies". The experts were interviewed, the necessary regulations were made in the questionnaire, and the final questionnaire to be used in the survey was given the final form.

\subsection{Sample}

For the application of survey, 300 community pharmacists randomly selected from Pharmacist Chamber of Ankara database were reached. The number of pharmacists who accepted to participate in the study was 244. Questionnaires were filled out by using face-to-face survey technique. 
The collected data were analyzed in SPSS 23.0. Chi-square test was applied to determine the meaningful differences between the answers given in the questionnaire.

Acknowledgements: The authors acknowledge all participant pharmacists.

Author contributions: Concept - G.Ö., S.D., G.G., M.B.U.; Design - G.G., M.B.U, S.D.; Supervision - G.Ö.; Resource G.Ö., S.D., G.G., M.B.U.; Materials - S.D., G.G.; Data Collection and/or Processing - S.D., G.G.; Analysis and/or Interpretation - G.G., M.B.U., S.D., G.Ö.; Literature Search - G.G. M.B.U., G.Ö.; Writing - G.G., M.B.U.; Critical Reviews - G.Ö., S.D., G.G., M.B.U.

Conflict of interest statement: The authors declared no conflict of interest in the manuscript.

\section{REFERENCES}

[1] T.C. Resmi Gazete, Beşeri Trbbi Ürünlerin Sınıflandırılmasına Dair Yönetmelik. http://www.resmigazete.gov.tr/eskiler/2005/02/20050217-4.htm, (accessed March 20, 2018).

[2] Aronson, JK. From prescription-only to over-the-counter medicines ('PoM to $\mathrm{P}^{\prime}$ ): time for an intermediate category. Br Med Bull. 2009; 90(1): 63-69.

[3] Kanzık, İ. OTC ve reklam. Aylık Gün Eczacilık Dergisi. 1993; 8.

[4] Gülpınar G, Özçelikay G. OTC drug regulations in Turkey: the opinions of community pharmacists and drug industry. Turk J Pharm Sci. 2015; 12(3): 267-278. [CrossRef]

[5] Türk Eczacıları Birliği AR-GE Birimi Rapor Dizisi-1, Reçetesiz İlaçlar ve İlaç Dışı Ürünler: Betimleme ve Müdahale 2009. http://95.0.129.28/tebdownload.php?file=images/upld2/tebfarmasotik, (accessed March 20, 2018).

[6] T.C. Resmi Gazete, Eczaclar ve Eczaneler Hakkında Yönetmelik. http://www.mevzuat.gov.tr/Metin.Aspx?MevzuatKod=7.5.19569\&sourceXmlSearch=eczac\%C4\%B1lar\&MevzuatI liski=0]. (accessed March 20, 2018).

[7] Atikeler EK, Özçelikay G. Comparison of pharmaceutical pricing and reimbursement systems in Turkey and certain EU countries. SpringerPlus. 2016; 5(1): 1876. [CrossRef]

[8] Dogac A, Yuksel M, Ertürkmen GL, Kabak Y, Namlı T, Yıldız MH, Ay Y, Ceyhan B, Hülür U, Öztürk H, Atabakan E. Healthcare Information Technology Infrastructures in Turkey. Yearbook of Medical Informatics. 2014;9(1):228-234. [CrossRef]

[9] Sağlık Uygulama Tebliğ. http://www.sutrehberi.com/sut-ana-metni, (accessed Febuary 23, 2018).

[10] Chang ZG, Kennedy DT, Holdford DA, Small RE. Pharmacists' knowledge and attitudes toward herbal medicine. Ann Pharmacother. 2000; 34(6): 710-715. [CrossRef]

[11] Chen X, Oi Lam ung C, Hu H, Liu X, Zhao J, Hu Y, Li P, Yang Q. Community pharmacists' perceptions about pharmaceutical care of traditional medicine products: A questionnaire-based cross-sectional study in Guangzhou, China. Evid Based Complement Alternat Med. 2016; 3: 1-10. [CrossRef]

[12] Naidu S, Wilkinson JM, Simpson MD. Attitudes of Australian pharmacists toward complementary and alternative medicines. Ann Pharmacother. 2005; 39(9): 1456-61. [CrossRef]

[13] Yüksel CA. Eczacıların reçetesiz ilaçların karşı tutumlarının genel tutum ortalamasından farkı ve tutumlarla demografik ve eczane özellikleri arasında ilişkinin incelenmesi üzerine pilot bir araştırma. J School Bus Adm Istanbul Uni. 2001; 12(38): 41-52.

[14] Kwan D, Boon HS, Hirschkorn K, Welsh S, Jurgens T, Eccott L, Heschuk S, Griener GG, Cohen-Kohler JC. Exploring consumer and pharmacist views on the professional role of the pharmacist with respect to natural health products: a study of focus groups. BMC Complement Altern Med. 2008; 8:40. [CrossRef]

[15] Resnik DB, Ranelli PL, Resnik SP. The conflict between ethics and business in community pharmacy: What about patient counseling? J Bus Ethics. 2000; 28: 179-186. [CrossRef]

[16] Boon H, Hirschkorn K, Griener G, Cali M. The ethics of dietary supplements and natural health products in pharmacy practice: A systematic documentary analysis. Int J Pharm Pract. 2009; 17(1): 31-38. [CrossRef]

[17] Anderson S. The state of the world's pharmacy: a portrait of the pharmacy profession. J Interprof Care. 2002; 16(4): 391-404. [CrossRef] 
[18] Clark BE, Mount JK. Pharmacy service orientation: A measure of organizational culture in pharmacy practice sites. Res Social Adm Pharm. 2006; 2(1): 110-128. [CrossRef]

[19] Hepler CD, Strand LM. Opportunities and responsibilities in pharmaceutical care. Am J Hosp Pharm. 1990; 47(3): 533-543.

[20] Taylor K, Harding G. The community pharmacist: over qualified dispenser or health professional?. J R Coll Gen Pract. 1989; 39(322): 209-210.

[21] Potnis PS. Masters Thesis. Ohio pharmacists' perceptions of over-the-counter drug advertising. College of Graduate Studies, The University of Toledo, Ohio, USA, 2012. http:/ / utdr.utoledo.edu/cgi/viewcontent.cgi?article=1427\&context=theses-dissertations, (acessed May 25, 2017).

[22] Sansgiry S, Sharp WT, Sansgiry SS. Accuracy of information on printed over-the-counter drug advertisements. Health Mark Q. 2008; 17(2):7-18. [CrossRef]

[23] Koh HL, Teo HH, Ng HL. Pharmacists' patterns of use, knowledge, and attitudes toward complementary and alternative medicine. J Altern Complement Med. 2003; 9(1): 51-63.

[24] Semple SJ, Hotham E, Rao D, Martin K, Smith CA, Bloustien FG. Community pharmacists in Australia: Barriers to information provision on complementary and alternative medicines. Pharm World Sci. 2006; 28: 366- 73. [CrossRef]

This is an open access article which is publicly available on our journal's website under Institutional Repository at http://dspace.marmara.edu.tr. 